\title{
Italian Guidelines in diagnosis and treatment of alopecia areata
}

\begin{abstract}
Alfredo ROSSI 1 *, Marta MUSCIANESE 1, Bianca M. PIRACCINI 2, Michela STARACE 2, Marta CARLESIMO 1 , Victor D. MANDEL ${ }^{3}$, Aurora ALESSANDRINI 2, Stefano CALVIERI ', Gemma CARO ', Andrea D'ARINO 1, Alessandro FEDERICO 1, Francesca MAGRI 1, Flavia PIGLIACELLI 1, Graziana AMENDOLAGINE 4, Maria C. ANNUNZIATA 5 , Maria C. ARISI ${ }^{6}$, Stefano ASTORINO ${ }^{7}$, Graziella BABINO ${ }^{8}$, Federico BARDAZZI ${ }^{2}$, Stefania BARRUSCOTTI 9 , Anna BELLONI FORTINA ${ }^{10}$, Alessandro BORGHI ${ }^{4}$, Francesca BRUNI ${ }^{2}$, Stefano CACCAVALE 8, Piergiacomo CALZAVARA-PINTON 6, Norma CAMELI 11, Michele CARDONE 1, Andrea CARUGNO ${ }^{9}$, Rosa COPPOLA ${ }^{12}$, Annunziata DATTOLA ${ }^{13}$, Maria B. DE FELICI DEL GIUDICE ${ }^{14}$, Antonella DI CESARE ${ }^{15}$, Emi DIKA 2, Donato DI NUNNO ${ }^{7}$, Roberto D'OVIDIO ${ }^{16}$, Gabriella FABBROCINI ${ }^{5}$, Claudio FELICIANI ${ }^{14}$, Elisabetta FULGIONE ${ }^{8}$, Marco GALLUZZO ${ }^{13}$, Simone GARCOVICH ${ }^{17}$, Valentina GARELLI 1, Cristina GUERRIERO 17, Katharina HANSEL 18, Michelangelo LA PLACA 2, Francesco LACARRUBBA ${ }^{19}$, Viviana LORA ${ }^{17}$, Elena MARINELLO 10, Matteo MEGNA 5, Giuseppe MICALI ${ }^{19}$, Cosimo MISCIALI 2, Paola MONARI 6, Giuseppe MONFRECOLA 5, Iria NERI 2 , Annamaria OFFIDANI 20, Gloria ORLANDO 10, Manuela PAPINI ${ }^{18}$, Annalisa PATRIZI ${ }^{2}$, Stefano PIASERICO ${ }^{10}$, Niccolò RIVETTI ${ }^{9}$, Oriana SIMONETTI ${ }^{20}$, Teodora R. STAN ${ }^{10}$, Luca STINGENI ${ }^{18}$, Marina TALAMONTI ${ }^{13}$, Francesco TASSONE 17, Lucia VILLA ${ }^{16}$, Colombina VINCENZI ${ }^{2}$, Maria C. FORTUNA ${ }^{1}$
\end{abstract}

${ }^{1}$ Division of Dermatology, Department of Internal Medicine and Medical Specialties, Sapienza University, Rome, Italy; ${ }^{2}$ Division of Dermatology, Department of Experimental, Diagnostic and Specialty Medicine, University of Bologna, Bologna, Italy; ${ }^{3}$ Unit of Dermatology, Surgical, Medical and Dental Department of Morphological Sciences Related to Transplant, Oncology and Regenerative Medicine, University of Modena and Reggio Emilia, Modena, Italy; ${ }^{4}$ Section of Dermatology and Infectious Diseases, Department of Medical Sciences, University of Ferrara, Ferrara, Italy; ${ }^{5}$ Section of Dermatology, Department of Clinical Medicine and Surgery, Federico II University, Naples, Italy; ${ }^{6}$ Department of Dermatology, ASST Spedali Civili of Brescia, University of Brescia, Brescia, Italy; 7 Unit of Dermatology and Venereology, Celio Military Hospital, Rome, Italy; ${ }^{8}$ Unit of Dermatology, Nuovo Policlinico, Luigi Vanvitelli University of Campania, Naples, Italy; ${ }^{9}$ Unit of Dermatology, S. Matteo University Polyclinic, IRCCS and Foundation, Pavia, Italy; ${ }^{10}$ Unit of Dermatology, Department of Medicine - DIMED, University of Padua, Padua, Italy; ${ }^{11}$ San Gallicano Dermatological Institute (IRCCS), Rome, Italy; ${ }^{12}$ Campus Bio-Medico University (Hospital), Rome, Italy; ${ }^{13}$ Department of Dermatology, Tor Vergata Polyclinic and University, Rome, Italy; ${ }^{14}$ Section of Dermatology, Department of Clinical and Experimental Medicine, University of Parma, Parma, Italy; ${ }^{15}$ Section of Dermatology, Department of Surgery and Translational Medicine, University of Florence, Florence, Italy; ${ }^{16}$ Private practitioner, Bari, Italy; ${ }^{17}$ Institute of Dermatology, A. Gemelli University Polyclinic, IRCCS and Foundation, Sacred Heart Carholic University, Rome, Italy; 18 Section of Dermatology, Department of Medicine, University of Perugia, Perugia, Italy; ${ }^{19 D e p a r t m e n t ~ o f ~}$ Dermatology, University of Catania, Catania, Italy; ${ }^{20}$ Unit of Dermatology, Department of Clinical and Molecular Sciences, Polytechnic Marche University, Ancona, Italy

*Corresponding author: Alfredo Rossi, Division of Dermatology, Department of Internal Medicine and Medical Specialties, Sapienza University, Viale del Policlinico 155, 00100 Rome, Italy. E-mail: alfredo.rossi@uniroma1.it

\section{A B S T R A C T}

Alopecia areata (AA) is an organ-specific autoimmune disorder that targets anagen phase hair follicles. The course is unpredictable and current available treatments have variable efficacy. Nowadays, there is relatively little evidence on treatment of AA from well-designed clinical trials. Moreover, none of the treatments or devices commonly used to treat AA are specifically approved by the Food and Drug Administration. The Italian Study Group for Cutaneous Annexial Disease of the Italian Society of dermatology proposes these Italian guidelines for diagnosis and 
treatment of Alopecia Areata deeming useful for the daily management of the disease. This article summarizes evidence-based treatment associated with expert-based recommendations.

(Cite this article as: Rossi A, Muscianese M, Piraccini BM, Starace M, Carlesimo M, Mandel VD, et al. Italian Guidelines in diagnosis and treatment of alopecia areata. G Ital Dermatol Venereol 2019;154:609-23. DOI: 10.23736/S0392-0488.19.06458-7)

KEY WORDS: Alopecia areata; Guideline; Autoimmunity.

\section{Introduction}

A lopecia areata (AA) is an organ-specific autoimmune disorder that targets anagen phase hair follicles. It has an unpredictable chronic-relapsing course, leading to transient non-scarring hair loss. Clinically, presentations vary considerably between individuals, ranging from small patches of alopecia to the loss of all body hair: alopecia universalis. ${ }^{1}$

Prevalence of AA has been estimated to about $0,2 \%$ of the general population and approximately $1.7-2.1 \%$ of the population experiences an episode of AA during their lifetime. ${ }^{2}$ AA can start at any age, however in the majority of patients, the onset is within the first three decades of life. There is none race or sex predilection. AA is often associated with other autoimmune diseases that must be investigated.

In most patients, disease severity is closely correlated with psychologic distress, and management of AA should include psychological support. The course of AA is not predictable, as spontaneous remission is possible, as well as a chronic course not responding to therapy. Up to 50 percent of patients with patchy AA experience spontaneous hair regrowth within one year, however, most will relapse months or years after remission. ${ }^{3}$

Due to the variable course of AA and the different degree of severity of hair loss, only a few well-designed reliable clinical trials are available in AA, which are limited by the low numbers of patients studied. ${ }^{4}$ The primary objective of the Italian guidelines is to make recommendations on the best treatment of AA to the Italian dermatological community, in collaboration with the expert in the field.

\section{Methodology of guideline preparation}

These guidelines are designed under the guidance of Italian Study Group on Cutaneous Annexial Disease of the Italian Society of Dermatology (SIDeMaST), taking in mind Italian regulations and treatments available.

This article summarizes evidence-based treatment associated with expert-based recommendations.

\section{Diagnosis}

The initial clinical examination should seek basic evidence for the diagnosis of AA, as well as screening for associated autoimmune diseases.

\section{Major objectives}

- to confirm the clinical diagnosis of AA, differentiating from other causes of hair loss;

- to specify the extent and location of hair loss involvement;

- to assess the activity of the disease by trichoscopy;

- to evaluate the prognosis depending on prognostic factors;

- to evaluate other associated conditions (Hashimoto thyroiditis, coeliac disease, etc.);

- to start treatment.

\section{Clinical examination and differentials}

\section{Medical history}

- it should specify the age of the first onset of hair loss and duration of the current episode;

- it should specify any associated symptoms (pain, pruritus);

- it should include a detailed medical history and drug intake (including response to therapy for AA);

- it should include a complete family medical history investigating autoimmune disorders;

- it should seek to evaluate the disease impact on patient's quality of life (DLQI).

\section{Physical examination}

AA typically presents with single or multiple round or oval patches of hair loss configuring (1) patchy alopecia. Other presentations include (2) alopecia totalis characterized by complete loss of scalp hair and (3) alopecia universalis characterized by loss of all body and scalp terminal hair; rarely various pattern of hair loss can be detected such as (4) ophiasis pattern: band-like pattern of hair loss along the periphery of occipital and temporal scalp, (5) ophiasis inversus-sisaipho pattern: band-like hair loss in the fronto- 


\section{COPYRIGHT $^{\circledR} 2019$ EDIZIONI MINERVA MEDICA}

parietal area sparing the temporal and occipital areas; (6) a diffuse pattern of hair loss and severe hair thinning that simulates androgenetic alopecia and telogen effluvium is typical of AA incognita; Finally a rare variant is (7) perinevoid AA. In some patients, AA may be localized to single hairy areas, such as the beard, eyebrows and eyelashes.

Usually, patients do not refer any symptoms, but occasionally some cutaneous dysesthesia may precede or be associated with hair loss. The skin of the affected patches is usually normal and smooth, rarely a pinkish coloration can be detected. White hairs initially may be spared, leading to the appearance of sudden graying of the hair in extensive AA (canieties subita, Maria Antonietta Phenomenon, sudden hair whiting); regrowth may begin with the appearance of fine white vellus hairs.

In addition, nails may be affected in AA, with geometric pitting being the most common sign, but also trachyonychia, mottled lunulae, and rarely onychomadesis may occur. ${ }^{1}$

\section{Trichoscopy}

Hair and scalp dermoscopy (trichoscopy) represents a fast and non-invasive technique for the evaluation of hair loss that allows magnified visualization of the hair and of the scalp skin. ${ }^{5}$ Nowadays, trichoscopy is the most important tool for diagnosis of AA; moreover it is essential in the assessment of disease activity and severity as well as therapeutic monitoring of AA.

In general, for AA diagnosis, short vellus hairs and yellow dots are the most sensitive markers, and black dots, broken hairs and tapering hairs are the most characteristic but not pathognomonic markers. ${ }^{6}$

TRICHOSCOPICAL SIGNS OF ACTIVE $\mathrm{AA}^{7}$

- Broken hairs: they result from irregular transverse fracture of the terminal hair of few millimeters from the scalp. The short length relates to the time between the latest event of disease activity and the examination moment;

- black dots: black dots or cadaverized hairs represent fragments of hair within the follicular ostium due to acute hair matrix damage: they indicate active hair loss;

- flame hair: they are a residue of hair caused by a rapid and severe trauma of anagen hairs detectable in $21 \%$ of patients affected by AA; 8

- exclamations mark hairs: mainly presents at the periphery of areas of hair loss, they are short, broken, dystrophic hairs whose distal ends are broader than the proximal ends. In our experience, they indicate a not recent mild damage to the follicle;

- tapered hairs: represent elongated exclamation mark hairs, corresponding to rapid catagen induction in AA. This category includes both "coudability hairs" and normal hairs with proximal tapered shape; they are usually detected in the perilesional area;

- Pohl-Pinkus constrictions: hairs characterized by zones of reduced hair thickness within the hair shaft. In AA the incidence rate of this feature ranges from 2 to $10 \%$ of patients;

- hair powder: fine pulverization of hair.

TRICHOSCOPICAL SIGNS OF LONG-LASTING INACTIVE AA ${ }^{7}$

- Yellow dots: correspond to follicular ostium filled with keratin and/or sebum. They are seen as rounded or polycyclic dots of different sizes, with color ranging from whitish to brownish-yellow, usually lacking hair or less common short, thin hair shaft. When numerous, they are distributed in a regular matter; due to the underdevelopment of sebaceous glands before puberty, yellow dots are not seen in children assuming a greyish color;

- exclamation mark hairs: can be present also in stable disease;

- short vellus hairs: short (less than $10 \mathrm{~mm}$ ) and hypo pigmented hairs.

TRICHOSCOPICAL SIGNS THAT INDICATE HAIR REGROWTH7 ${ }^{7}$

- Upright regrowing hairs: they are healthy regrowing hairs that have a straight-up position and they can be confused with short vellus hairs;

- pigtail hairs (circle hairs): short re-growing coiled hairs with tapered ends.

\section{Reflectance confocal microscopy (RCM)9-12}

RCM is a non-invasive imaging technique for in vivo evaluation of the skin and the observation of cell morphology with a nearly histological resolution. Hair shaft thickness, medulla, cortex and cuticle can be evaluated with RCM and the hair shaft structure abnormalities could be visualized, as in trichoscopy, but with greater detail.

$\mathrm{RCM}$ features that can be observed in AA are:

- yellow dots: round luminal structures surrounded by follicular epithelium and filled by highly bright material corresponding to keratotic material and/or sebum;

- broken hairs: absence of follicular openings and presence of dysmorphic hairs that appear less bright then healthy hairs;

- exclamations mark hairs: short hyporeflective dysmorphic hairs whose distal ends are broader than the proximal ends; 


\section{COPYRIGHT $^{(} 2019$ EDIZIONI MINERVA MEDICA}

ROSSI

ALOPECIA AREATA

- black dots: round luminal structures with inside the remnant of dysmorphic hairs that look less reflective then healthy hairs;

- short vellus hairs: short hairs with a reduction of the caliber of the hair shaft in comparison to normal hairs;

- pigtail hairs (circle hairs): short coiled hairs with a reduction of the caliber of the hair shaft $(<$ of $20 \mu \mathrm{m}$ in diameter) and tapered ends;

- upright regrowing hairs: straight-up hairs with a reduction of the caliber of the hair shaft $(<$ of $20 \mu \mathrm{m}$ in diameter);

- Pohl-Pinkus constrictions: hairs of normal thickness with irregularly placed thinner areas of the hair shaft $(<$ of $20 \mu \mathrm{m}$ in diameter);

- inflammatory cells infiltration of epidermis, adnexal structure and upper dermis: small, single to aggregate and bright round cellular structure visible in the epidermis between keratinocytes, and/or within the adnexal epithelium, and/or in the upper dermis;

- rimmed dermal papillae: bright rimming of the dermal papillae that correspond on histology to the integrity and pigmentation of the dermoepidermal junction;

- melanophages: pumped, polygonal to stellate bright cellular structure in the upper dermis;

- dermal fibers degeneration: Coarse and thick dermal bundles of the upper dermis. This feature can be seen as diffused in the upper dermis or located around adnexal structures.

Dilated vessels: horizontally oriented "canalicular" structures in the upper dermis.

In conclusion RCM is fundamental in the estimation of dermal fibrosis and inflammation measures, which are not assessable with tricoscopy, but are important parameters in the follow-up evaluation.

\section{Scale of severity and prognosis}

AA is a non-scarring alopecia and the regrowth capacity of hairs is preserved.

The severity of AA is assessed by the Severity of Alopecia Tool (SALT) and graded according to the guidelines of the National Alopecia Areata Foundation ${ }^{13}$ as follows:

- S0: no hair loss;

- S1: less than $25 \%$ hair loss;

- S2: 26-50\% hair loss;

- S3: 51-75\% hair loss;

- S4: 76-99\% hair loss;

- S5: 100\% hair loss.

According to prognosis AA has been historically categorized into four types by Ikeda ${ }^{14}$ and after on this basis,
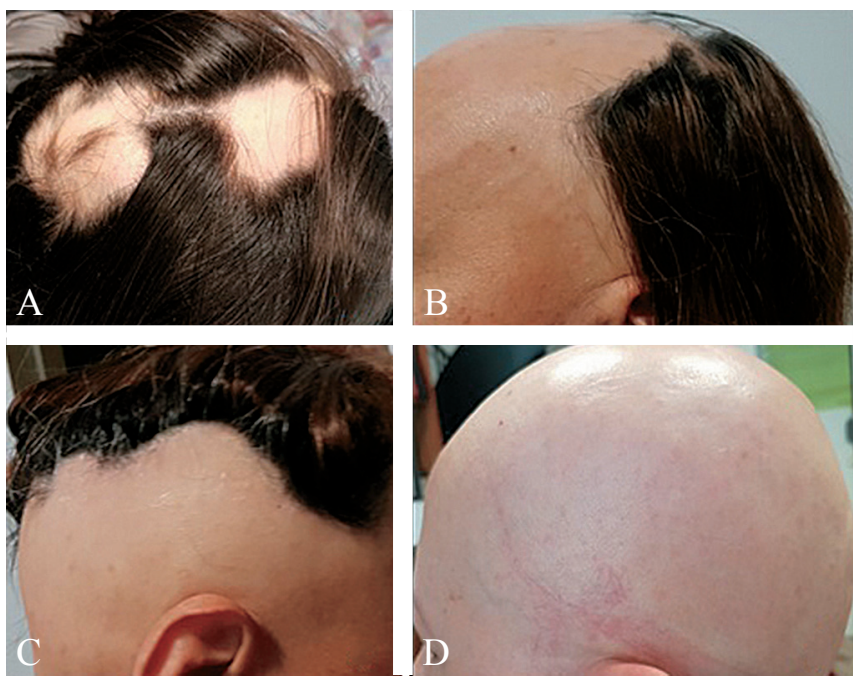

Figure 1.-Clinical types of alopecia areata. A) patchy alopecia; B) sisaipho pattern; C) ophiasis pattern; D) alopecia totalis.

Rook identified three types: type I associated with atopy, starts in early life, and has a poor prognosis, type II that starts after the age of 20, no associations are described and usually has a favorable prognosis and type III, starts in adulthood has an intermediate prognosis and it is associated with autoimmune endocrine diseases (Figure 1).15

Disease severity at onset of the disease is the strongest predictor of long-term outcome, especially alopecia totalis or alopecia universalis. Other factors that are associated with a worse prognosis are onset in childhood, duration of more than one year, band-like involvement of the peripheral temporal and occipital scalp (ophiasis pattern), association with nail signs, association with atopy and family history of AA.

Trichoscopic markers of activity can also be useful in predicting the course of disease and the assessment of response to therapy. A large-scale study on the scalp of 300 Asian patients showed that black dots, yellow dots, and short vellus hairs correlated with the severity of disease, and black dots, tapering hairs, broken hairs, and short vellus hairs correlated with disease activity. ${ }^{6}$ In the author's experience, also flame hairs and hair powder relates to disease activity.

\section{Differential diagnosis}

Several diseases need to be considered in the differential diagnosis of AA.

Patchy hair loss should be differentiated from:

- trichotillomania: this condition can be difficult to dis- 


\section{COPYRIGHT $^{\circledR} 2019$ EDIZIONI MINERVA MEDICA}

tinguish from AA and a coexistent of the 2 condition is possible, especially in children. The main differences are 2: the incomplete nature of the hair loss, that produce a bizarre shape of the alopecic areas and the fact that broken hairs are usually firmly anchored in the scalp, unlike exclamation mark hairs, rending the pull test negative;

- tinea capitis: inflammation, scaling, pustules on the patchy hair loss suggest tinea capitis but the signs may be vanished.

Diffuse forms of AA need differential diagnosis with:

- telogen effluvium and anagen effluvium (drug and chemotherapy-induced);

- loose anagen hair.

\section{Associated diseases}

AA may be associated to several autoimmune and autoinflammatory disorders, such as thyroiditis and vitiligo, rheumatoid arthritis, systemic lupus erythematous, psoriasis, allergic rhinitis, type I diabetes, coeliac disease, myasthenia gravis, ulcerative colitis and scleroderma. ${ }^{1}$ Furthermore, a high prevalence of other comorbid conditions has been found among patients affected by $\mathrm{AA}^{16}$ (Table I).

Similarly to other autoimmune diseases, AA is characterized by a strong genetic predisposition and several genes contribute to this risk. In AA three genome-wide association studies showed that twelve independent genetic loci, including loci encoding genes in both innate and adaptive immunity, are involved. In particular, among the HLA class II genes the DR4, DR5, DQ3, DQ7 and DPW4 alleles are strongly associated. ${ }^{17,18}$

Interestingly an increased risk for autoimmune type

TABLE I. - Summary of comorbid conditions in alopecia areata.

Thyroid disease

Systemic lupus erythematosus

Type 1 diabetes

Diabetes mellitus

Rheumatoid arthritis

Vitiligo

Psoriasis

Myasthenia gravis

Coeliac disease

Ulcerative colitis

Atopy (allergic rhinitis, asthma, eczema)

Contact dermatitis

Mental health problems (depression or anxiety)

Hyperlipidemia

Hypertension

Anemia

Gastroesophageal reflux disease
I diabetes mellitus has also been reported in relatives of patients with AA. ${ }^{19}$ Iron deficiency was more common in women with AA than the general population in one small case serie..$^{20}$ The implication of genes located on chromosome 21 is suggested by the association between an increased risk for AA and genetic disorders such as Down's syndrome (trisomy 21) and polyglandular autoimmune syndrome type I, caused by a mutation in the autoimmune regulator (AIRE) gene on chromosome 21.21-23 These relationships between a broad spectrum of autoimmune diseases imply a need for surveillance of patients for potential secondary autoimmune disease processes.

After diagnosis is made, a detailed personal and family history for atopy, thyroid disease, coeliac and other autoimmune disorders should be obtained.

In the author's opinion, all patients should be investigated at least for autoimmune thyroiditis and coeliac disease throw blood research of specific autoantibodies (anti-thyroid peroxidase antibodies and thyroglobulin antibodies and IgA and IgG antiendomysial antibodies and antitransglutaminase antibodies).

\section{Investigations}

In most cases of AA, diagnosis can be made through obtaining a sound history and an accurate clinical inspection, especially since trichoscopy is available. A trichogram usually is not necessary. A positive pull test with dystrophic anagen or telogen hairs at the margins of the patches suggests activity of the disease along with trichoscopic signs of activity. Sometimes other investigations can be useful to rule out other differentials when clinical and trichoscopic features are not indicative.

When the diagnosis is uncertain appropriate tests may include microscopic examination of hair shafts and fungal culture, serology for lupus erythematosus or syphilis and scalp biopsy.

Histopathologic findings in AA change depending on the disease phase in which the biopsy is performed. In the early acute stage, the main feature is a peribulbar and intrabulbar lymphocytic infiltrate surrounding the anagen and/or catagen follicles described as "a swarm of bees." The inflammatory infiltrate consists primarily of $\mathrm{T}$ cells (CD4+, CD8+) but Langerhans cells, eosinophils, mast cells, and plasma cells can also be detected. This lymphocytic attack causes apoptosis, necrosis, and microvesiculation of the follicular epithelium and anagen hairs cycle through catagen then into telogen.

In long-standing AA, inflammation is not constantly present. Horizontal sections are in these cases preferred 


\section{COPYRIGHT $^{\circledR} 2019$ EDIZIONI MINERVA MEDICA}

to vertical section as they provide more details, showing a significant decrease in the number of terminal hairs and in the anagen/telogen ratio. A chronic peribulbar lymphocytic infiltrate around the miniaturized hairs may also be observable. ${ }^{24}$

\section{Therapeutic management}

\section{Counseling}

An exhaustive explanation of the nature and course of the disease and the available treatments, discussing realistic expectations for treatment, is essential.

The quality of life should also be evaluated in patients with AA through DLQI questionnaire: hair loss can have significant effects on patients' quality of life and psychologic support is an important component of therapy. Although AA has few physically harmful effects, it may lead to psychological consequences, including high levels of anxiety and depression. Studies of adolescents suffering from AA have found increased rates of psychiatric symptoms. ${ }^{25,} 26$ Moreover, the failure treatment effects, not uncommon, may leave patients very distressed, particularly in children, adolescents, and young women. AA can also cause physical disability, such as when there is eyelash involvement, loss of nasal hairs, or marked nail dystrophy (twenty-nail dystrophy).

The problem with treatment AA is that its course is unpredictable. Treatment of AA is not mandatory, consequently the decision to treat is a shared decision with the patient; in view of the variable efficacy of currently available treatments and their respective side effects, the clinician has an important role in making conscious patients of the positive and negative aspects of active treatment.

Patients must be informed about risks and benefits of treatment and that spontaneous remission occurs in up to variable percentage of patients with limited disease and the disease often recurs once the treatment is discontinued. It must be clear that none of the available treatments can modify the long-term course of the disease and a treatment with a specific indication for AA is still missing.

\section{Objectives}

- Investigate and diagnose associated autoimmune diseases;

- choose the specific treatment based mainly on age activity and severity and of the disease;

- arrest the progression of the disease;

- induce of hair regrowth;

- limit side effects related to the therapy;

- improve the quality of life of patients.

\section{Available therapies}

\section{Intralesional corticosteroids}

Patients with isolated patches of hair loss or less than $25 \%$ of scalp hair loss are the best candidates of injections, due to the difficulty in tolerating a high number of injections in case of large areas. The affected area may be pretreated with a topical anesthetic cream under occlusion, or a frozen gauze can be applied for a few seconds on the scalp before the injection to decrease pain.

There are no randomized trials on the efficacy of intralesional corticosteroids in AA. However, two nonrandomized comparative studies found both intralesional triamcinolone acetonide and its less soluble derivative triamcinolone hexacetonide effective in inducing re-growth of hair tufts with the effect of a single injection sometimes persisting for 9 months. ${ }^{27,} 28$

Intralesional treatment with triamcinolone acetonide by a needleless device has also been studied and showed good results. ${ }^{29}$

We recommend not to exceed the following concentrations of triamcinolone acetonide injected in the upper subcutis: 2.5 to $5 \mathrm{mg} / \mathrm{mL}$ on the face for eyebrow involvement and 5 to $10 \mathrm{mg} / \mathrm{mL}$ on the scalp. Multiple sites $1 \mathrm{~cm}$ apart are injected with small volumes of product. The total amount of triamcinolone administered should not exceed $40 \mathrm{mg}$ per treatment session. Multiple treatment sessions can be planned after 30-45 days from each other. Intralesional steroid therapy should be discontinued if there is no response after six months. ${ }^{30}$ The well-known rare adverse effects of intralesional corticosteroids include reversible skin atrophy, telangiectasias and hypopigmentation, particularly in patients with type III-VI of Fitzpatrick skin type classification and disturbance of the menstrual cycle. In some specific sites such as eyebrows, it has been documented that intralesional corticosteroids may cause cataract and elevation of intraocular pressure. ${ }^{31}$ Finally, two cases of anaphylaxis due to intralesional triamcinolone acetonide in literature are reported. ${ }^{32,33} \mathrm{~A}$ signed informed consent should be asked before performing the procedure, which needs some experience.

\section{Potent topical corticosteroids}

They are considered first-line therapy in children and in adults with who refuse intralesional injections. ${ }^{34-36}$ While high potency topical corticosteroids are commonly used to treat AA, evidence for their effectiveness is limited, and data on efficacy are available only from two 12-week 


\section{COPYRIGHT $^{(\odot)} 2019$ EDIZIONI MINERVA MEDICA}

randomized trials. In the first one, 70 patients with patchy hair loss were randomly assigned to apply either placebo or $0.25 \%$ desoximetasone cream twice daily. ${ }^{37}$ After 12 weeks of therapy $58 \%$ of patients treated with desoximetasone experienced complete regrowth of hair compared with $39 \%$ of patients treated with placebo. These results failed to reach statistical significance. In the second study, 105 patients with localized AA were randomized to treatment with betamethasone valerate $0.1 \%$ foam applied twice daily, intralesional triamcinolone acetonide $10 \mathrm{mg} /$ $\mathrm{mL}$ administered every three weeks, or topical tacrolimus $0.1 \%$ ointment applied twice daily. Results showed more than $75 \%$ hair regrowth in $54 \%$ of patients treated with betamethasone valerate, $60 \%$ of patients treated with triamcinolone acetonide, and $0 \%$ of patients treated with topical tacrolimus. ${ }^{38}$ In a trial, 34 moderate to severe AA patients were randomly assigned to clobetasol propionate $0.05 \%$ application on one side of the scalp and a vehicle to the other side. After 12 weeks of treatment, more sites treated with clobetasol had at least $50 \%$ regrowth of hair. ${ }^{39}$ Clobetasol propionate cream placed under an occlusive dressing was effective in $28,5 \%$ of the 28 patients of a study. 40

After hair regrowth, potent topical corticosteroids must be tapered. There is no univocal protocol for this operation, which therefore must be based on the patient's characteristics and on the physician's experience, individualizing the approach.

Similar to intralesional corticosteroids, side effects of topical therapy include folliculitis, local skin atrophy, telangiectasias, dyspigmentation, and rarely adrenal suppression. Patients should be instructed to wash the head after 12 hours from the application, in order to avoid steroidinduced scalp folliculitis.

\section{Systemic glucocorticoids}

Olsen et al. investigate in a prospective study of 32 patients with AA, including 16 patients with alopecia totalis or universalis, the efficacy of oral prednisone tapered from $40 \mathrm{mg}$ to $0 \mathrm{mg}$ over the course of six weeks. $30-47 \%$ of patients treated showed more than $25 \%$ hair regrowth. 41

The only one controlled trial of 43 patients that were treated with pulse $200 \mathrm{mg}$ oral prednisolone or placebo once weekly for 3 months. After six months of prednisolone treatment, patients showed better results than those treated with placebo, but this was not statistically significant. 42

Regimens that involve high-dose pulsed oral glucocorticoids or even intravenous regimens may also induce hair regrowth. ${ }^{42-48}$ Overall extensive patchy alopecia response better than alopecia totalis, universalis and ophiasis variety to these treatments.

Although significant side-effects have not yet been reported with pulsed systemic corticosteroids, the wellknown side effects associated with these agents and recurrence of the disease after their suspension limit duration of therapy. 49,50

\section{Topical immunotherapy}

Topical immunotherapy is the preferred first-line treatment for patients with extensive chronic AA, assessed by trichoscopical signs. The precise mechanism of action of topical immunotherapy is not completely understood, but an immunomodulatory effect on the peribulbar infiltrate plays the key role. A potent contact allergen such as diphenylcyclopropenone (DPCP) or squaric acid dibutyl ester (SADBE) is weekly applied on the scalp to stimulate an allergic mild contact dermatitis that in the end results in hair regrowth. ${ }^{51,52}$

A recent systematic review and meta-analysis of forty-five studies evaluating contact immunotherapy with 1-chloro, 2, 4, dinitrobenzene (DNCB), diphenylcyclopropenone (DPCP) or squaric acid dibutyl ester (SADBE) for patchy AA, alopecia totalis, and alopecia universalis analyzed the results on 2227 patients. The overall rate of complete hair regrowth was $32.3 \%$ while the overall rate of any hair regrowth was $65.5 \%$. Similarly, to other therapies, patchy AA had better response rates than alopecia totalis or universalis. Recurrences after treatment discontinuation were common (recurrence rates were 38.3\% among patients receiving maintenance treatment and $49.0 \%$ among those not receiving maintenance treatment). 53

Topical immunotherapy can be performed with DPCP or SADBE, while DNCB was found mutagenic. DPCP is usually preferred over SADBE because it is less expensive and more stable in solution. It must be stored away from light to avoid its degradation.

Protocol for DPCP use was described by Happle in $1983 ;^{54}$ first of all, patients have to be sensitized by the application of a $2 \%$ DPCP solution to a small area, usually $4 \times 4 \mathrm{~cm}$ on the scalp, for 48 hours. After two weeks, treatment can be started with application of DPCP to the affected areas, in a concentration that elicits a mild dermatitis, washed off after 24 hours. During the contact between skin and allergen, sun exposure is interdicted. The protocol for sensitization and treatment with SADBE is similar.

In the majority of studies if there was no response after six months therapy has to be discontinued; however, as hair regrowth with topical immunotherapy can occur even 


\section{COPYRIGHT $^{\circledR} 2019$ EDIZIONI MINERVA MEDICA}

lately, a 12-18 months of therapy length are suggested before assessing efficacy. In a large case series, hair regrowth occurred in about $30 \%$ of patients after 6 months of treatment but this increased to $78 \%$ after 32 months of treatment, suggesting that extension of treatment is useful. 55

The main adverse effect of this treatment is the induction of a severe contact dermatitis characterized by vesicular or bullous lesions. In this case, the contact allergen should be washed from the skin and treatment with a topical corticosteroid should be initiated. Other possible side effects include occipital and or cervical lymphadenopathy (common), urticaria, dyschromia and vitiligo, especially in darker skin. ${ }^{56-59}$ The discontinuation of topical immunotherapy is recommended in pregnancy because until up today, no studies have defined its safety profile in this population.

\section{Topical anthralin}

Anthralin or Dithranol is a topical drug historically used for psoriasis therapy. Anthralin action is carried out by reducing inflammation. Evidence of its efficacy for AA is restricted to a small number of case series with inadequate controls. ${ }^{60,61}$ Studies have suggested that anthralin may be effective high concentrations ( 0.5 or $1 \%$ cream) applied for short periods (20 to 30 minutes daily) on the alopecic scalp, in the so-called short-contact therapy. The time of contact is increased by 10 minutes every two weeks up to one hour or to the time required to produce a mild dermatitis. Otherwise, treatment can also be started with application of anthralin $0.1 \%$ to the scalp for 10 to 20 minutes and then gradually increasing this time of contact, reaching tolerance for leaving anthralin on overnight. Evidence shows that anthralin have to elicit a mild irritant reaction to be effective. Anthralin should be used for at least three months. In 2015 a retrospective study demonstrated that combination therapy with DPCP and anthralin is more effective than DPCP monotherapy. ${ }^{62}$

Overall, a less percentage of patients with extensive AA achieved a good clinical response rate compared with intralesional corticosteroids and topical immunotherapy, and anthralin therapy is suggested in children who are too young to be treated with topical steroids.

Anthralin will stain hair, skin, and clothing brows, limiting its use in fair-haired patients.

\section{Minoxidil}

Data on effectiveness of topical minoxidil in AA resulting from randomized trials are contradictive, except for the evidence that minoxidil is not effective in alopecia totalis and universalis. ${ }^{63}$ In fact, a study that shows a significantly higher hair regrowth in patchy alopecia treated with topical $1 \%$ minoxidil compared with placebo, ${ }^{64}$ while other data suggest the opposite results. ${ }^{65,66}$

However, a dose-response effect is documented, with a higher efficacy of $5 \%$ minoxidil compared to $1 \%$ minoxidil. 67

Indication for the use of topical minoxidil in AA is when hair regrowth has started, in order to increase length and thickness of the new hair.

\section{Biologic drugs}

In the last years, several biologic agents have been considered as possible treatments for AA, thanks to their effectiveness in several other autoimmune diseases. However, clinical trials on some antitumor necrosis factor (TNF)- $\alpha$ inhibitors such as infliximab and etanercept, or monoclonal antibody such efalizumab and alefacept did not show the expected results. ${ }^{68-70}$ Moreover, cases of acute AA occurring during treatment with biologic agents are reported in literature. . $^{7-78}$

\section{JANUS KINASE INHIBITORS}

A relatively new class of biologic agents, Janus kinase (JAK) inhibitors appear to be effective in AA. Janus kinases are critical for a large family of proinflammatory cytokines signaling. The first JAK inhibitors have been approved by the FDA for the treatment of myelofibrosis, then rheumatoid arthritis. ${ }^{79}$ The most studied JAK inhibitor for the treatment of AA is an oral selective JAK $1 / 3$ inhibitor: tofacitinib administere 5 to $10 \mathrm{mg}$ twice daily. ${ }^{80-86}$ The results of these studies support the effectiveness in both patchy alopecia and alopecia totalis/universalis after only 4 months of treatment. Lower efficacy was achieved in patients with a disease episode longer than 10 years $(32 \%$ of clinical response rate).

Recently, two small case series were conducted to asses efficacy of oral tofacitinib in pediatric population. In the first study all of 8 children experienced partial hair regrowth; 87 in the other series, complete or partial hair regrowth occurred in 3 of 4 preadolescent children treated for refractory alopecia totalis or universalis; of note, the non-responder was treated with half dose compared to the other children ( $5 \mathrm{mg}$ daily instead of $5 \mathrm{mg}$ twice daily). ${ }^{88}$ Although no significant adverse effects were reported in either study, in our opinion, further studies are needed to confirm the safety and efficacy of tofacitinib before its use for pediatric alopecia. Moreover, adverse effects reported 


\section{COPYRIGHT $^{(\odot)} 2019$ EDIZIONI MINERVA MEDICA}

during treatment with oral tofacitinib for other diseases include severe infections, malignancy and laboratory abnormalities. 89,90

In the open-label pilot study testing the effectiveness in AA of another JAK inhibitor, oral ruxolitinib at the dose of $20 \mathrm{mg}, 75 \%$ of patients achieved at least $50 \%$ hair regrowth after three to six months of therapy. ${ }^{89}$ Several other case series and case reports support the use of this drug in AA. ${ }^{11-95}$

The topical formulations of these new drugs (tofacitinib $2 \%$ ointment, ruxolitinib $1 \%$ ointment) are very interesting in order to minimize the adverse effects without losing effectiveness; nowadays few data are available but they seem to be a promising treatment option in both adults and pediatric AA patients. ${ }^{96-101}$

These drugs can be administered in both active and chronic phase of AA.

\section{Systemic immunosuppressive agents}

\section{Methotrexate}

Methotrexate (10-25 mg per week) can be useful in AA, particularly when used in association with systemic glucocorticoids (clinical response rate of 63\%). ${ }^{102}$ However, in order to achieve these results, therapy should be continued for three to twelve months, with an increased risk of drug toxicity and disease-recurrence commonly appears after discontinuation of methotrexate.

\section{Sulfasalazine}

Several uncontrolled studies reported that this immunosuppressive drug is an efficacious therapy in approximately $25 \%$ of patients with AA. ${ }^{103-106}$ The open-label study conducted on 22 patients, $68.2 \%$ of patients responded to therapy $(27.3 \%$ achieved complete hair regrowth, and $40.9 \%$ achieved partial hair regrowth), concluding that sulfasalazine could be considered as a therapeutic alternative in the treatment of AA. ${ }^{103}$ Side effects of sulfasalazine may occur during treatment. Thus, complete blood cell counts and liver function tests should be closely monitored.

\section{AZATHIOPRINE}

Azathioprine is an immunosuppressant agent that has been shown effective in stimulating hair regrowth in some patients with moderate to severe AA. However, the studies conducted are small and uncontrolled (almost $43 \%$ of the 14 recruited patients experienced a good clinical regrowth on $75 \%$ or more of the scalp). Of note, the occurrence of side effects such as diarrhea, liver enzyme elevation, pancreatitis, and bone marrow suppression resulted in treatment interruption in four patients $(28 \%){ }^{107,} 108$

\section{Miscellaneous treatment}

In the decades a miscellaneous group of topical and oral drugs with less scientific valence have been tested with variable results.

Aromatherapy refers to the use of aromatic plant-based essential oils (thyme, rosemary, lavender, and cedarwood) for topical application onto the scalp. A randomized, double-blind, controlled trial of 7-month duration on 86 patients from almost 2 decades ago, showed benefit of aromatherapy concluding that is a safe and effective treatment for AA. 109 We do not recommend this therapy in AA.

Bexarotene is a selective retinoid that induces T-cell apoptosis. A phase I/II, randomized, single-blind trial, was conducted in 2010. Forty-two patients applied 1\% bexarotene gel twice daily for 6 months, to one side of the scalp. Five out $42(12 \%)$ had $50 \%$ or more partial hair regrowth on the treated side, and 6 of $42(14 \%)$ on both sides including 3 complete responders. ${ }^{110}$ No further studies have been performed to suggest this drug a potential treatment for AA.

\section{LASER THERAPY}

The excimer laser is a form of ultraviolet laser that emits monochromatic ultraviolet B (UVB) light at a wavelength of $308 \mathrm{~nm}$. It is supposed that its mechanism of action in AA is related to T cell apoptosis. ${ }^{111}$ In the literature, some small studies and case reports showed an improvement of patchy AA after excimer laser treatment, also in children (60\% response rate). However, alopecia totalis and alopecia universalis did not benefits from this treatment. $111-114$

The Infrared diode laser showed a good rate of response leading to a complete or partial regrowth in 32 out of 34 treated patches. ${ }^{115}$

\section{EZETIMIBE-SIMVASTATIN}

The statin family, usually used for reducing atherogenesis, have immunomodulatory activities. In a prospective study, 19 patients assumed ezetimibe-simvastatin $(10 \mathrm{mg} / 40 \mathrm{mg})$ once-daily for 24 weeks achieving $20 \%$ hair regrowth in 14 cases and $70 \%$ of hair regrowth in 9 cases. ${ }^{116}$ Subsequently, a second phase of the study was conducted and patients 


\section{COPYRIGHT $^{\circledR} 2019$ EDIZIONI MINERVA MEDICA}

were divided into responders who continued treatment for an additional 24 weeks and responders who stopped therapy. In different case reports, alopecia totalis and alopecia universalis were successfully treated with simvastatin/ ezetimibe. ${ }^{117,} 118$ Recently, a prospective open study was performed in 14 patients with recalcitrant AA and authors concluded that the remission rate was unsatisfactory. ${ }^{119}$ In a prospective observational study on 12 patients treated with simvastatin/ezetimibe $40 / 10 \mathrm{mg}$ over a period of 6 months, $67 \%$ had no hair regrowth, $24 \%$ transient diffuse or patchy hair regrowth, and $24 \%$ patchy regrowth of pigmented hair. Side effects included myalgia reported by $24 \%$ of patients and elevation of creatine phosphokinase in 1. Authors conclude that simvastatin/ezetimibe is not effective for treatment of AA. ${ }^{120}$ We do not consider simvastatin/ezetimibe a suggested therapy for AA.

\section{LOW-DOSE RECOMBINANT INTERLEUKIN-2}

Interleukin (IL)-2, a cytokine involved in regulatory $\mathrm{T}$ cell homeostasis, is historically used for the treatment of advanced melanoma and renal cell carcinoma. A small pilot study on five patients with AA showed a partial response in 4 of 5.121 The possible toxicity of low-dose recombinant IL-2 therapy is, in our opinion, a limiting factor to suggest this therapy in AA.

\section{Platelet-RICH PLASMa (PRP)}

In the pilot study to investigate the efficacy and safety of PRP on AA, 45 patients with chronic and recurring disease were randomized to receive intralesional injections of PRP, triamcinolone acetonide or placebo on one half of their scalp. Platelet-rich plasma injection was most effective in inducing hair regrowth and decreasing scalp burning or itching sensation. 122 The main side effects of PRP are pain, edema, tenderness, and rarely scalp psoriasiform reaction and scarring. Further studies are needed to suggest this expensive therapy as a possible treatment for AA, based on its possible immunomodulatory action.

\section{PHOTOCHEMOTHERAPY}

Psoralen plus ultraviolet A (PUVA) photochemotherapy has been largely studied for treatment of AA.123-126 Some of these studies were uncontrolled and reported efficacy rates of 60 to $65 \%$ while others did not confirm these results, showing efficacy rates no better than the natural course of the disease without therapy. Moreover, cutaneous malignancy as long-term PUVA adverse effect cannot be ignored. We do not suggest PUVA as a therapy for AA.

\section{CALCINEURIN INHIBITORS}

Topical pimecrolimus and topical tacrolimus have not shown any result in AA treatment. ${ }^{127-129}$ Likewise, topical cyclosporine is not effective. ${ }^{130,131}$ Data from case series and uncontrolled studies on oral cyclosporine at high doses documented a possible hair regrowth in AA. ${ }^{132-135}$ Similar to other immunosuppressive therapies, the potential serious adverse effects preclude a long-term therapy and must be considered.

\section{FECAL MICROBIOTA TRANSPLANTATION}

Two patients affected by alopecia universalis experienced hair regrowth after fecal microbiota transplantation.

Authors suggest that gut microbiota may have immunomodulatory effects in autoimmune conditions like AA and further studies may elucidate this event. 136

FUMARIC ACID ESTERS

Fumaric aid esters are commonly used for psoriasis treatment, thanks to their activities on cytokine networks. ${ }^{137}$ For these immunomodulatory effects, Niculescu et al. has conducted a retrospective analysis of the application of fumaric acid esters in 13 patients with AA. ${ }^{138}$ Six (46\%) patients had a response; 3 of them experiencing full regrowth of hair. Similarly to other treatments, patchy AA responded better than alopecia totalis or universalis: All patients experienced a new episode of hair loss after cessation of treatment, which is not advisable in AA, also considering the risk of fumaric acid esters toxicity.

OTHERS

Photodynamic therapy, azelaic acid, garlic gel, triiodothyronine, isoprinosine and total glucosides of paeony are other treatment studied with no reported efficacy in AA. 139

\section{Topical prostaglandin analogues}

There are no conventional treatments for eyelash alopecia. Analogues of prostaglandin F2a, bimatoprost and latanoprost, have been studied for eyelash loss with conflicting results. In literature, a 2-16 week controlled study shows no benefit with either latanoprost or bimatoprost ${ }^{140}$ and a partial regrowth in only one of 26 patients. ${ }^{141}$ Lengthening the duration of treatment with latanoprost $0.005 \%$ ophthalmic solution every night for two years in 40 patients, a complete regrowth was achieved in $17.5 \%$, moderate regrowth in $27.5 \%$, slight regrowth in $30 \%$ and no response 


\section{COPYRIGHT $^{\circledR} 2019$ EDIZIONI MINERVA MEDICA}

in $25 \%$. In the control group, none of the patients treated with injections of $0.5 \mathrm{mg} / \mathrm{cm} 2$ of triamcinolone acetonide, reached similar results. ${ }^{142}$

\section{Cosmetic options}

Wigs, headscarves, hairpieces, shaving of the scalp, tattoos, tricopigmentation, protein powders, sprays, or pigmented lotions designed to make the hair appear more full are very helpful to decrease the patient's perception of AA and should be suggested, as well as the application of false eyelashes and eyebrows.

\section{Treatment management}

In the Authors' opinion, the treatment approach of patients with AA should differ based upon the age, the clinical extent and the activity of the disease.

In patients younger than 10-years, regardless of the clinical manifestation, topical high potency corticosteroids are the preferred treatment. Eventually, minoxidil 5\% can be added. ${ }^{143}$ Anthralin can be considered in very young children (1-3 years) (Figure 2).

Over 10-years old of age, the activity and extent of disease should be considered.

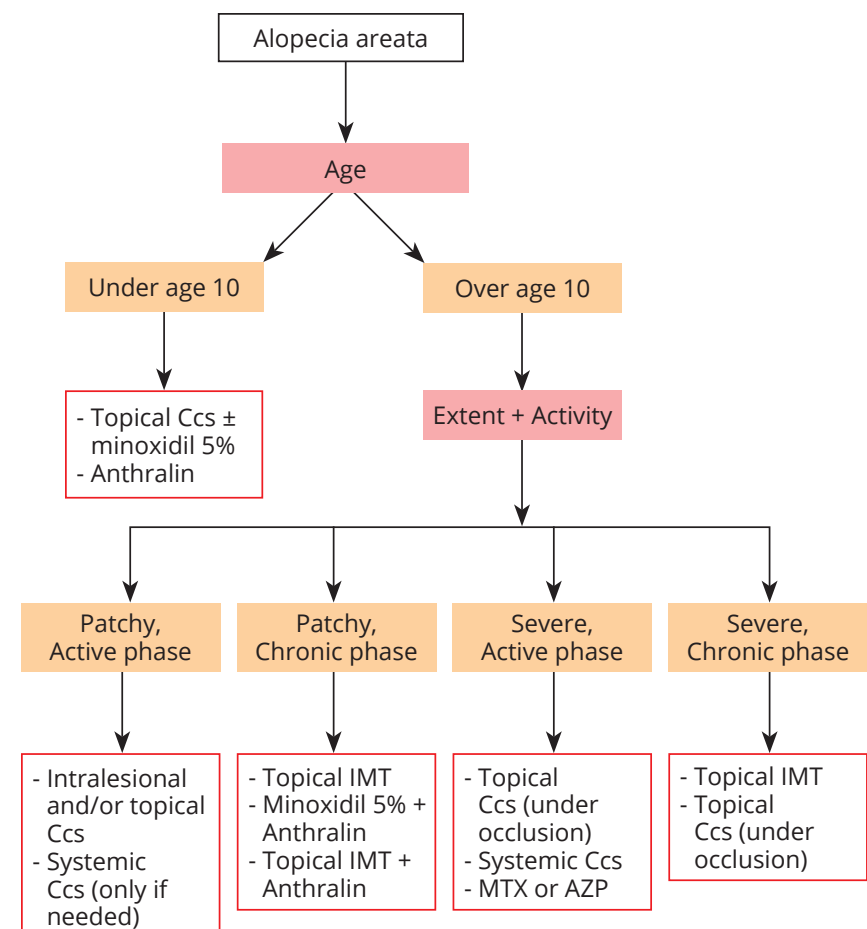

Figure 2.-Treatment algorithm for the management of alopecia areata. Ccs: corticosteroids; IMT: immunotherapy; MTX: methotrexate; AZP: azathioprine.

\section{Patchy AA (less than 50\% of scalp hair loss) in active phase}

Intralesional and/or topical corticosteroids are definitely the first-line treatment when trrichoscopical signs of activity are present in the patch of hair loss, such as black dots, broken hairs, flame hair, hair powder. In specific cases, a short courses of systemic glucocorticoid can be added in order to temporarily halt disease progression.

We recommend systemic glucocorticoids only as a temporary measure to contain rapidly progressing active disease, when several trichoscopical signs of activity can be detected, with a conspicuous loss of hair; after reaching this goal, these patients may be switched to alternative therapies. Common treatments course are $50 \mathrm{mg}$ of prednisone per day in adults or $1 \mathrm{mg} / \mathrm{kg}$ per day in children tapered over four to six weeks or $40 \mathrm{mg}$ triamcinolone acetonide intramuscular injection every 15 days tapered over 6-12 weeks.

As mentioned above, desoximetasone, betamethasone valerate and clobetasol propionate are the only potent topical corticosteroids evaluated in the studies and thus recommended.

However, based on the Author's experiences, even the association of four different potent topical corticosteroids in different formulations can be considered. In this therapeutic schedule, the patients are instructed to apply topical corticosteroids in pairs, daily on alternate evenings. Therefore, they apply triamcinolone acetonide solution and immediately after betamethasone cream on the first day. After one day off treatment, the association between salicylic acid and alcinonide lotion is administered immediately prior to halometasone cream; they must have care in applying the lotion followed by the cream in order to facilitate the absorption of halometasone. This protocol can be helpful to avoid a sudden decrease in response (tachyphylaxis).

High potency topical corticosteroids should be used for 3 to 6 months before judging its effectiveness, and can be extended also in the maintenance treatment with lengthening of time of application.

\section{Patchy AA (less than 50\% of scalp hair loss) in chronic phase}

Patients with Patchy AA in chronic stage, or patients not responding to topical corticosteroids, can be treated with topical immunotherapy with the same regimen described for patients with more extensive disease. Another option in this category should be the association between topical minoxidil 5\% and topical anthralin as well as the association between topical immunotherapy and topical anthralin. 


\section{COPYRIGHT $^{(\odot)} 2019$ EDIZIONI MINERVA MEDICA}

Severe AA (more than 50\% of scalp hair loss) in active phase

In patients with extensive AA that shows trichoscopical signs of activity (black dots, broken hairs, flame hair, hair powder), the first-line treatment should be systemic glucocorticoid, prescribed in short course as mentioned above.

In addition, high potency topical corticosteroids such as desoximetasone, betamethasone valerate and clobetasol propionate placed under an occlusive dressing to increase their effects, should be used. Even in these patients the authors have experiences with the association of four different potent topical corticosteroids in different formulations (triamcinolone acetonide, betamethasone, association between salicylic acid and alcinonide, halometasone).

If corticosteroids failed in to contain the disease, a second line choice could be a systemic immunosuppressant, among methotrexate and azathioprine. However, take into account all the possible adverse effects of these therapies, an accurate evaluation of the patient is essential before starting these treatments.

\section{Severe AA (more than 50\% of scalp hair loss) in chronic} phase

Topical immunotherapy is the treatment of choice in these patients with by severe AA with trichoscopical signs of chronic phase (yellow dots, exclamation mark point hair, short vellus hair). Alternatively, high potency topical corticosteroids in occlusion can be proposed.

\section{Conclusions}

The main goals of treatment in AA are to block the immune system attack and to stimulate the regrowth of hair. This can be effective, especially for people with milder forms of the disease, while extensive forms often fail to respond to therapy.

Only a few treatments for AA have been evaluated in randomized clinical trials and the majority of them are characterized by few recruited patients, with several studies having major limitations that hinder the interpretation of the results. Therefore, there is relatively little evidence on treatment of AA from well-designed clinical trials.

Moreover, none of the treatments or devices commonly used to treat AA are specifically approved by the Food and Drug Administration (FDA) and are not refunded by the Italian National Health Service.

For all these reasons the Authors consider the Italian
Guidelines useful and needed for the daily management of the disease and for the future acknowledge of AA a real immunological disease by Italian National Health Service.

As the response to treatment of AA is variable, and some patients may choose do not undergo under treatment, a conscientious approach evaluating all the mentioned aspects is essential when dealing with patients with all types and severity of AA.

\section{References}

1. Hordinsky MK. Overview of alopecia areata. J Investig Dermatol Symp Proc 2013;16:S13-5.

2. Darwin E, Arora H, Hirt PA, Wikramanayake TC, Jimenez JJ. A review of monochromatic light devices for the treatment of alopecia areata. Lasers Med Sci 2018;33:435-44.

3. Messenger AG, McKillop J, Farrant P, McDonagh AJ, Sladden M. British Association of Dermatologists' guidelines for the management of alopecia areata 2012. Br J Dermatol 2012;166:916-26.

4. Delamere FM, Sladden MM, Dobbins HM, Leonardi-Bee J. Interventions for alopecia areata. Cochrane Database Syst Rev 2008;(2):CD004413.

5. Lacarrubba F, Micali G, Tosti A. Scalp dermoscopy or trichoscopy. Curr Probl Dermatol 2015;47:21-32.

6. Inui S, Nakajima T, Nakagawa K, Itami S. Clinical significance of dermoscopy in alopecia areata: analysis of 300 cases. Int J Dermatol 2008;47:688-93.

7. Waśkiel A, Rakowska A, Sikora M, Olszewska M, Rudnicka L. Trichoscopy of alopecia areata: an update. J Dermatol 2018;45:692-700.

8. Miteva M, Tosti A. Flame Hair. Skin Appendage Disord 2015;1:105-9.

9. Mandel VD, Cinotti E, Benati E, Labeille B, Ciardo S, Vaschieri C, et al. Reflectance confocal microscopy and optical coherence tomography for the diagnosis of bullous pemphigoid and pemphigus and surrounding subclinical lesions. J Eur Acad Dermatol Venereol 2018;32:1562-9.

10. Ardigò M, Tosti A, Cameli N, Vincenzi C, Misciali C, Berardesca E. Reflectance confocal microscopy of the yellow dot pattern in alopecia areata. Arch Dermatol 2011;147:61-4.

11. Rudnicka L, Olszewska M, Rakowska A. In vivo reflectance confocal microscopy: usefulness for diagnosing hair diseases. J Dermatol Case Rep 2008;2:55-9.

12. Ardigò $M$, Agozzino $M$, Franceschini $C$, Donadio $C$, Abraham LS, Barbieri L, et al. Reflectance confocal microscopy for scarring and non-scarring alopecia real-time assessment. Arch Dermatol Res 2016;308:309-18.

13. Olsen EA, Hordinsky MK, Price VH, Roberts JL, Shapiro J, Canfield $\mathrm{D}$, et al.; National Alopecia Areata Foundation. Alopecia areata investigational assessment guidelines - part II. J Am Acad Dermatol 2004;51:440-7. 14. Ikeda $T$. A new classification of alopecia areata. Dermatologica 1965;131:421-45.

15. Rook AJ. Common baldness and alopecia areata. In: Rook AJ, ed. Recent advantages in dermatology. Oxford: Blackwell; 1977. P. 236-28

16. Huang KP, Mullangi S, Guo Y, Qureshi AA. Autoimmune, atopic, and mental health comorbid conditions associated with alopecia areata in the United States. JAMA Dermatol 2013;149:789-94.

17. Tafazzoli A, Forstner AJ, Broadley D, Hofmann A, Redler S, Petukhova L, et al. Genome-Wide MicroRNA Analysis Implicates miR-30b/d in the Etiology of Alopecia Areata. J Invest Dermatol 2018;138:549-56.

18. Megiorni F, Pizzuti A, Mora B, Rizzuti A, Garelli V, Maxia C, et al. Genetic association of HLA-DQB1 and HLA-DRB1 polymorphisms with alopecia areata in the Italian population. Br J Dermatol 2011;165:823-7. 


\section{COPYRIGHT $^{(\odot)} 2019$ EDIZIONI MINERVA MEDICA}

ALOPECIA AREATA

ROSSI

19. Wang SJ, Shohat T, Vadheim C, Shellow W, Edwards J, Rotter JI. Increased risk for type I (insulin-dependent) diabetes in relatives of patients with alopecia areata (AA). Am J Med Genet 1994;51:234-9.

20. White MI, Currie J, Williams MP. A study of the tissue iron status of patients with alopecia areata. Br J Dermatol 1994;130:261-3.

21. Du Vivier A, Munro DD. Alopecia areata, autoimmunity, and Down's syndrome. BMJ 1975;1:191-2.

22. Schepis C, Barone C, Siragusa M, Pettinato R, Romano C. An updated survey on skin conditions in Down syndrome. Dermatology 2002;205:234-8.

23. Collins SM, Dominguez M, Ilmarinen T, Costigan C, Irvine AD. Dermatological manifestations of autoimmune polyendocrinopathy-candidiasis-ectodermal dystrophy syndrome. Br J Dermatol 2006;154:1088-93.

24. Dy LC, Whiting DA. Histopathology of alopecia areata, acute and chronic: why is it important to the clinician? Dermatol Ther (Heidelb) 2011;24:369-74.

25. Madani S, Shapiro J. Alopecia areata update. J Am Acad Dermatol 2000;42:549-66, quiz 567-70.

26. Gilhar A, Paus R, Kalish RS. Lymphocytes, neuropeptides, and genes involved in alopecia areata. J Clin Invest 2007;117:2019-27.

27. Porter D, Burton JL. A comparison of intra-lesional triamcinolone hexacetonide and triamcinolone acetonide in alopecia areata. Br J Dermatol 1971;85:272-3.

28. Kubeyinje EP. Intralesional triamcinolone acetonide in alopecia areata amongst 62 Saudi Arabs. East Afr Med J 1994;71:674-5.

29. Abell E, Munro DD. Intralesional treatment of alopecia areata with triamcinolone acetonide by jet injector. Br J Dermatol 1973;88:55-9.

30. Alkhalifah A, Alsantali A, Wang E, McElwee KJ, Shapiro J. Alopecia areata update: part II. Treatment. J Am Acad Dermatol 2010;62:191-202, quiz 203-4.

31. Carnahan MC, Goldstein DA. Ocular complications of topical, peri-ocular, and systemic corticosteroids. Curr Opin Ophthalmol 2000;11:478-83.

32. Downs AM, Lear JT, Kennedy CT. Anaphylaxis to intradermal triamcinolone acetonide. Arch Dermatol 1998;134:1163-4.

33. Laing ME, Fallis B, Murphy GM. Anaphylactic reaction to intralesional corticosteroid injection. Contact Dermat 2007;57:132-3.

34. Lenane P, Macarthur C, Parkin PC, Krafchik B, DeGroot J, Khambalia A, et al. Clobetasol propionate, $0.05 \%$, vs hydrocortisone, $1 \%$, for alopecia areata in children: a randomized clinical trial. JAMA Dermato 2014; $150: 47-50$.

35. Harrison S, Sinclair R. Optimal management of hair loss (alopecia) in children. Am J Clin Dermatol 2003;4:757-70.

36. Hawit F, Silverberg NB. Alopecia areata in children. Cutis 2008;82:104-10.

37. Charuwichitratana S, Wattanakrai P, Tanrattanakorn S. Randomized double-blind placebo-controlled trial in the treatment of alopecia areata with $0.25 \%$ desoximetasone cream. Arch Dermatol 2000;136:1276-7.

38. Kuldeep C, Singhal H, Khare AK, Mittal A, Gupta LK, Garg A. Randomized comparison of topical betamethasone valerate foam, intralesional triamcinolone acetonide and tacrolimus ointment in management of localized alopecia areata. Int J Trichology 2011;3:20-4.

39. Tosti A, Iorizzo M, Botta GL, Milani M. Efficacy and safety of a new clobetasol propionate $0.05 \%$ foam in alopecia areata: a randomized, double-blind placebo-controlled trial. J Eur Acad Dermatol Venereol 2006;20:1243-7.

40. Tosti A, Piraccini BM, Pazzaglia M, Vincenzi C. Clobetasol propionate $0.05 \%$ under occlusion in the treatment of alopecia totalis/universalis. J Am Acad Dermatol 2003;49:96-8.

41. Olsen EA, Carson SC, Turney EA. Systemic steroids with or without $2 \%$ topical minoxidil in the treatment of alopecia areata. Arch Dermatol 1992;128:1467-73.

42. Kar BR, Handa S, Dogra S, Kumar B. Placebo-controlled oral pulse prednisolone therapy in alopecia areata. J Am Acad Dermatol 2005;52:287-90.

43. Vañó-Galván S, Hermosa-Gelbard Á, Sánchez-Neila N, Miguel-Gómez L, Saceda-Corralo D, Rodrigues-Barata R, et al. Pulse corticosteroid therapy with oral dexamethasone for the treatment of adult alopecia totalis and universalis. J Am Acad Dermatol 2016;74:1005-7.

44. Burton JL, Shuster S. Large doses of glucocorticoid in the treatment of alopecia areata. Acta Derm Venereol 1975;55:493-6.

45. Friedli A, Labarthe MP, Engelhardt E, Feldmann R, Salomon D, Saurat JH. Pulse methylprednisolone therapy for severe alopecia areata: an open prospective study of 45 patients. J Am Acad Dermatol 1998;39:597-602.

46. Perriard-Wolfensberger J, Pasche-Koo F, Mainetti C, Labarthe MP, Salomon D, Saurat JH. Pulse of methylprednisolone in alopecia areata. Dermatology 1993;187:282-5.

47. Sharma VK. Pulsed administration of corticosteroids in the treatment of alopecia areata. Int J Dermatol 1996;35:133-6.

48. Sharma VK, Gupta S. Twice weekly $5 \mathrm{mg}$ dexamethasone oral pulse in the treatment of extensive alopecia areata. J Dermatol 1999;26:562-5.

49. Winter RJ, Kern F, Blizzard RM. Prednisone therapy for alopecia areata. A follow-up report. Arch Dermatol 1976;112:1549-52.

50. Alabdulkareem AS, Abahussein AA, Okoro A. Severe alopecia areata treated with systemic corticosteroids. Int J Dermatol 1998;37:622-4.

51. Rokhsar CK, Shupack JL, Vafai JJ, Washenik K. Efficacy of topical sensitizers in the treatment of alopecia areata. J Am Acad Dermatol 1998;39:751-61.

52. van der Steen PH, van Baar HM, Perret CM, Happle R. Treatment of alopecia areata with diphenylcyclopropenone. J Am Acad Dermatol 1991;24:253-7.

53. Lee S, Kim BJ, Lee YB, Lee WS. Hair Regrowth Outcomes of Contact Immunotherapy for Patients With Alopecia Areata: A Systematic Review and Meta-analysis. JAMA Dermatol 2018;154:1145-51.

54. Happle R, Hausen BM, Wiesner-Menzel L. Diphencyprone in the treatment of alopecia areata. Acta Derm Venereol 1983;63:49-52.

55. Wiseman MC, Shapiro J, MacDonald N, Lui H. Predictive model for immunotherapy of alopecia areata with diphencyprone. Arch Dermatol 2001;137:1063-8.

56. Tosti A, Guerra L, Bardazzi F. Contact urticaria during topical immunotherapy. Contact Dermat 1989;21:196-7.

57. Alam M, Gross EA, Savin RC. Severe urticarial reaction to diphenylcyclopropenone therapy for alopecia areata. J Am Acad Dermatol 1999;40:110-2.

58. Henderson CA, Ilchyshyn A. Vitiligo complicating diphencyprone sensitization therapy for alopecia universalis. Br J Dermatol 1995;133:496-7.

59. MacDonald-Hull SP, Cotterill JA, Norris JF. Vitiligo following diphencyprone dermatitis. Br J Dermatol 1989;120:323.

60. Wu SZ, Wang S, Ratnaparkhi R, Bergfeld WF. Treatment of pediatric alopecia areata with anthralin: A retrospective study of 37 patients. Pediatr Dermatol 2018;35:817-20.

61. Fiedler-Weiss VC, Buys CM. Evaluation of anthralin in the treatment of alopecia areata. Arch Dermatol 1987;123:1491-3.

62. Durdu M, Özcan D, Baba M, Seçkin D. Efficacy and safety of diphenylcyclopropenone alone or in combination with anthralin in the treatment of chronic extensive alopecia areata: a retrospective case series. J Am Acad Dermatol 2015;72:640-50.

63. Vestey JP, Savin JA. A trial of 1\% minoxidil used topically for severe alopecia areata. Acta Derm Venereol 1986;66:179-80.

64. Fenton DA, Wilkinson JD. Topical minoxidil in the treatment of alopecia areata. Br Med J (Clin Res Ed) 1983;287:1015-7.

65. Price VH. Double-blind, placebo-controlled evaluation of topical minoxidil in extensive alopecia areata. J Am Acad Dermatol 1987;16:730-6. 66. Ranchoff RE, Bergfeld WF, Steck WD, Subichin SJ. Extensive alo- 


\section{COPYRIGHT $^{(\odot)} 2019$ EDIZIONI MINERVA MEDICA}

pecia areata. Results of treatment with 3\% topical minoxidil. Cleve Clin J Med 1989;56:149-54.

67. Fiedler-Weiss VC. Topical minoxidil solution (1\% and $5 \%)$ in the treatment of alopecia areata. J Am Acad Dermatol 1987;16:745-8.

68. Shin BS, Furuhashi T, Nakamura M, Torii K, Morita A. Impaired inhibitory function of circulating CD4+CD25+ regulatory $\mathrm{T}$ cells in alopecia areata. J Dermatol Sci 2013;70:141-3.

69. Strober BE, Siu K, Alexis AF, Kim G, Washenik K, Sinha A, et al. Etanercept does not effectively treat moderate to severe alopecia areata: an open-label study. J Am Acad Dermatol 2005;52:1082-4.

70. Strober BE, Menon K, McMichael A, Hordinsky M, Krueger G, Panko J, et al. Alefacept for severe alopecia areata: a randomized, doubleblind, placebo-controlled study. Arch Dermatol 2009;145:1262-6.

71. Chaves Y, Duarte G, Ben-Said B, Tebib J, Berard F, Nicolas JF. Alopecia areata universalis during treatment of rheumatoid arthritis with antiTNF-alpha antibody (adalimumab). Dermatology 2008;217:380.

72. Pelivani N, Hassan AS, Braathen LR, Hunger RE, Yawalkar N. Alopecia areata universalis elicited during treatment with adalimumab. Dermatology 2008;216:320-3.

73. Garcia Bartels N, Lee HH, Worm M, Burmester GR, Sterry W, Blume-Peytavi U. Development of alopecia areata universalis in a patien receiving adalimumab. Arch Dermatol 2006;142:1654-5.

74. Fabre C, Dereure O. Worsening alopecia areata and de novo occurrence of multiple halo nevi in a patient receiving infliximab. Dermatology 2008;216:185-6.

75. Ettefagh L, Nedorost S, Mirmirani P. Alopecia areata in a patient using infliximab: new insights into the role of tumor necrosis factor on human hair follicles. Arch Dermatol 2004;140:1012.

76. Tosti A, Pazzaglia M, Starace M, Bellavista S, Vincenzi C, Tonelli G. Alopecia areata during treatment with biologic agents. Arch Dermatol 2006;142:1653-4.

77. Pan Y, Rao NA. Alopecia areata during etanercept therapy. Ocul Immunol Inflamm 2009;17:127-9.

78. Posten W, Swan J. Recurrence of alopecia areata in a patient receiving etanercept injections. Arch Dermatol 2005;141:759-60.

79. O'Shea JJ, Kontzias A, Yamaoka K, Tanaka Y, Laurence A. Janus kinase inhibitors in autoimmune diseases. Ann Rheum Dis 2013;72(Supp 2):ii111-5.

80. Liu LY, Craiglow BG, Dai F, King BA. Tofacitinib for the treatment of severe alopecia areata and variants: A study of 90 patients. J Am Acad Dermatol 2017;76:22-8

81. Craiglow BG, King BA. Killing two birds with one stone: oral tofacitinib reverses alopecia universalis in a patient with plaque psoriasis. J Invest Dermatol 2014;134:2988-90.

82. Dhayalan A, King BA. Tofacitinib Citrate for the Treatment of Nail Dystrophy Associated With Alopecia Universalis. JAMA Dermatol 2016;152:492-3

83. Craiglow BG, Liu LY, King BA. Tofacitinib for the treatment of alopecia areata and variants in adolescents. J Am Acad Dermatol 2017;76:29-32

84. Gupta AK, Carviel JL, Abramovits W. Efficacy of tofacitinib in treatment of alopecia universalis in two patients. J Eur Acad Dermatol Venereol 2016;30:1373-8.

85. Ibrahim O, Bayart CB, Hogan S, Piliang M, Bergfeld WF. Treatment of Alopecia Areata With Tofacitinib. JAMA Dermatol 2017;153:600-2.

86. Jabbari A, Sansaricq F, Cerise J, Chen JC, Bitterman A, Ulerio G, et al. An Open-Label Pilot Study to Evaluate the Efficacy of Tofacitinib in Moderate to Severe Patch-Type Alopecia Areata, Totalis, and Universalis. J Invest Dermatol 2018;138:1539-45.

87. Castelo-Soccio L. Experience with oral tofacitinib in 8 adolescent patients with alopecia universalis. J Am Acad Dermatol 2017;76:754-5.

88. Craiglow BG, King BA. Tofacitinib for the treatment of alopecia areata in preadolescent children. J Am Acad Dermatol 2019;80:568-70.
89. Papp KA, Menter A, Strober B, Langley RG, Buonanno M, Wolk R, et al. Efficacy and safety of tofacitinib, an oral Janus kinase inhibitor, in the treatment of psoriasis: a Phase $2 \mathrm{~b}$ randomized placebo-controlled dose-ranging study. Br J Dermatol 2012;167:668-77.

90. Wollenhaupt J, Silverfield J, Lee EB, Curtis JR, Wood SP, Soma K, et al. Safety and efficacy of tofacitinib, an oral janus kinase inhibitor, for the treatment of rheumatoid arthritis in open-label, longterm extension studies. J Rheumatol 2014;41:837-52.

91. Mackay-Wiggan J, Jabbari A, Nguyen N, Cerise JE, Clark C, Ulerio $\mathrm{G}$, et al. Oral ruxolitinib induces hair regrowth in patients with moderateto-severe alopecia areata. JCI Insight 2016;1:e89790.

92. Xing L, Dai Z, Jabbari A, Cerise JE, Higgins CA, Gong W, et al. Alopecia areata is driven by cytotoxic T lymphocytes and is reversed by JAK inhibition. Nat Med 2014;20:1043-9.

93. Harris JE, Rashighi M, Nguyen N, Jabbari A, Ulerio G, Clynes R, et al. Rapid skin repigmentation on oral ruxolitinib in a patient with coexistent vitiligo and alopecia areata (AA). J Am Acad Dermatol 2016;74:370-1.

94. Liu LY, King BA. Ruxolitinib for the treatment of severe alopecia areata. J Am Acad Dermatol 2019;80:566-8.

95. Pieri L, Guglielmelli P, Vannucchi AM. Ruxolitinib-induced reversal of alopecia universalis in a patient with essential thrombocythemia. Am J Hematol 2015;90:82-3.

96. Liu LY, Craiglow BG, King BA. Tofacitinib $2 \%$ ointment, a topical Janus kinase inhibitor, for the treatment of alopecia areata: A pilot study of 10 patients. J Am Acad Dermatol 2018;78:403-404.e1, e1.

97. Craiglow BG, Tavares D, King BA. Topical Ruxolitinib for the Treatment of Alopecia Universalis. JAMA Dermatol 2016;152:490-1.

98. Bokhari L, Sinclair R. Treatment of alopecia universalis with topical Janus kinase inhibitors - a double blind, placebo, and active controlled pilot study. Int J Dermatol 2018;57:1464-70.

99. Bayart CB, DeNiro KL, Brichta L, Craiglow BG, Sidbury R. Topical Janus kinase inhibitors for the treatment of pediatric alopecia areata. J Am Acad Dermatol 2017;77:167-70.

100. Putterman E, Castelo-Soccio L. Topical $2 \%$ tofacitinib for children with alopecia areata, alopecia totalis, and alopecia universalis. J Am Acad Dermatol 2018;78:1207-1209.e1, e1.

101. Cheng MW, Kehl A, Worswick S, Goh C. Successful Treatment of Severe Alopecia Areata With Oral or Topical Tofacitinib. J Drugs Dermatol 2018;17:800-3.

102. Phan K, Ramachandran V, Sebaratnam DF. Methotrexate for alopecia areata: A systematic review and meta-analysis. J Am Acad Dermatol 2019;80:120-127.e2, e2.

103. Aghaei S. An uncontrolled, open label study of sulfasalazine in severe alopecia areata. Indian J Dermatol Venereol Leprol 2008;74:611-3.

104. Ellis CN, Brown MF, Voorhees JJ. Sulfasalazine for alopecia areata. J Am Acad Dermatol 2002;46:541-4.

105. Bakar $\mathrm{O}$, Gurbuz $\mathrm{O}$. Is there a role for sulfasalazine in the treatment of alopecia areata? J Am Acad Dermatol 2007;57:703-6.

106. Rashidi T, Mahd AA. Treatment of persistent alopecia areata with sulfasalazine. Int J Dermatol 2008;47:850-2.

107. Vañó-Galván S, Hermosa-Gelbard Á, Sánchez-Neila N, Miguel-Gómez L, Saceda-Corralo D, Rodrigues-Barata R, et al. Treatment of recalcitrant adult alopecia areata universalis with oral azathioprine. J Am Acad Dermatol 2016;74:1007-8.

108. Farshi S, Mansouri P, Safar F, Khiabanloo SR. Could azathioprine be considered as a therapeutic alternative in the treatment of alopecia areata? A pilot study. Int J Dermatol 2010;49:1188-93.

109. Hay IC, Jamieson M, Ormerod AD. Randomized trial of aromatherapy. Successful treatment for alopecia areata. Arch Dermatol 1998;134:1349-52.

110. Talpur R, Vu J, Bassett R, Stevens V, Duvic M. Phase I/II randomized bilateral half-head comparison of topical bexarotene $1 \%$ gel for alopecia areata. J Am Acad Dermatol 2009;61:592.e1-9. 


\section{COPYRIGHT $^{(\odot)} 2019$ EDIZIONI MINERVA MEDICA}

111. Zakaria W, Passeron T, Ostovari N, Lacour JP, Ortonne JP. 308$\mathrm{nm}$ excimer laser therapy in alopecia areata. J Am Acad Dermatol 2004;51:837-8.

112. Al-Mutairi N. 308-nm excimer laser for the treatment of alopecia areata. Dermatol Surg 2007;33:1483-7.

113. Gundogan $C$, Greve B, Raulin C. Treatment of alopecia areata with the 308-nm xenon chloride excimer laser: case report of two successful treatments with the excimer laser. Lasers Surg Med 2004;34:86-90.

114. Al-Mutairi N. 308-nm excimer laser for the treatment of alopecia areata in children. Pediatr Dermatol 2009;26:547-50.

115. Waiz M, Saleh AZ, Hayani R, Jubory SO. Use of the pulsed infrared diode laser $(904 \mathrm{~nm})$ in the treatment of alopecia areata. J Cosmet Laser Ther 2006;8:27-30.

116. Lattouf C, Jimenez JJ, Tosti A, Miteva M, Wikramanayake TC, Kittles C, et al. Treatment of alopecia areata with simvastatin/ezetimibe. J Am Acad Dermatol 2015;72:359-61.

117. Ali A, Martin JM 4th. Hair growth in patients alopecia areata totalis after treatment with simvastatin and ezetimibe. J Drugs Dermatol 2010;9:62-4.

118. Robins DN. Case reports: alopecia universalis: hair growth following initiation of simvastatin and ezetimibe therapy. J Drugs Dermatol 2007;6:946-7.

119. Choi JW, Suh DW, Lew BL, Sim WY. Simvastatin/Ezetimibe Therapy for Recalcitrant Alopecia Areata: An Open Prospective Study of 14 Patients. Ann Dermatol 2017;29:755-60.

120. Freitas Gouveia M, Trüeb RM. Unsuccessful Treatment of Alopecia Areata with Simvastatin/Ezetimibe: experience in 12 Patients. Skin Appendage Disord 2017;3:156-60.

121. Castela E, Le Duff F, Butori C, Ticchioni M, Hofman P, Bahadoran $\mathrm{P}$, et al. Effects of low-dose recombinant interleukin 2 to promote T-regulatory cells in alopecia areata. JAMA Dermatol 2014;150:748-51.

122. Trink A, Sorbellini E, Bezzola $P$, Rodella L, Rezzani R, Ramot $Y$, et al. A randomized, double-blind, placebo- and active-controlled, half-head study to evaluate the effects of platelet-rich plasma on alopecia areata. $\mathrm{Br}$ J Dermatol 2013;169:690-4.

123. Claudy AL, Gagnaire D. PUVA treatment of alopecia areata. Arch Dermatol 1983;119:975-8.

124. Lassus A, Eskelinen A, Johansson E. Treatment of alopecia areata with three different PUVA modalities. Photodermatol 1984;1:141-4.

125. van der Schaar WW, Sillevis Smith JH. An evaluation of PUVAtherapy for alopecia areata. Dermatologica 1984;168:250-2.

126. Mitchell AJ, Douglass MC. Topical photochemotherapy for alopecia areata. J Am Acad Dermatol 1985;12:644-9.

127. Rigopoulos D, Gregoriou S, Korfitis C, Gintzou C, Vergou T, Katrinaki A, et al. Lack of response of alopecia areata to pimecrolimus cream. Clin Exp Dermatol 2007;32:456-7.
128. Price VH, Willey A, Chen BK. Topical tacrolimus in alopecia areata. J Am Acad Dermatol 2005;52:138-9.

129. Feldmann KA, Kunte C, Wollenberg A, Wolfe H. Is topical tacrolimus effective in alopecia areata universalis? $\mathrm{Br} \mathrm{J}$ Dermatol 2002;147:1031-2.

130. Gilhar A, Pillar T, Etzioni A. Topical cyclosporin A in alopecia areata. Acta Derm Venereol 1989;69:252-3.

131. Mauduit G, Lenvers P, Barthélémy $H$, Thivolet $J$. [Treatment of severe alopecia areata with topical applications of cyclosporin A]. Ann Dermatol Venereol 1987;114:507-10. French.

132. Açıkgöz G, Calışkan E, Tunca M, Yeniay Y, Akar A. The effect of oral cyclosporine in the treatment of severe alopecia areata. Cutan Ocul Toxicol 2014;33:247-52.

133. Yeo IK, Ko EJ, No YA, Lim ES, Park KY, Li K, et al. Comparison of High-Dose Corticosteroid Pulse Therapy and Combination Therapy Using Oral Cyclosporine with Low-Dose Corticosteroid in Severe Alopecia Areata. Ann Dermatol 2015;27:676-81.

134. Jang YH, Kim SL, Lee KC, Kim MJ, Park KH, Lee WJ, et al. A Comparative Study of Oral Cyclosporine and Betamethasone Minipulse Therapy in the Treatment of Alopecia Areata. Ann Dermatol 2016;28:569-74.

135. Kim BJ, Min SU, Park KY, Choi JW, Park SW, Youn SW, et al. Combination therapy of cyclosporine and methylprednisolone on severe alopecia areata. J Dermatolog Treat 2008;19:216-20.

136. Rebello D, Wang E, Yen E, Lio PA, Kelly CR. Hair Growth in Two Alopecia Patients after Fecal Microbiota Transplant. ACG Case Rep J 2017;4:e107.

137. Wollina U. Fumaric acid esters in dermatology. Indian Dermatol Online $\mathrm{J}$ 2011;2:111-9.

138. Niculescu L, Heppt MV, Varga R, Steckmeier S, Wolff H, Tietze JK. Retrospective analysis of the application of fumaric acid esters in 13 patients with alopecia areata. Eur J Dermatol 2018;28:376-7.

139. Hordinsky M, Donati A. Alopecia areata: an evidence-based treatment update. Am J Clin Dermatol 2014;15:231-46.

140. Roseborough I, Lee H, Chwalek J, Stamper RL, Price VH. Lack of efficacy of topical latanoprost and bimatoprost ophthalmic solutions in promoting eyelash growth in patients with alopecia areata. J Am Acad Dermatol 2009; 60:705-6.

141. Faghihi G, Andalib F, Asilian A. The efficacy of latanoprost in the treatment of alopecia areata of eyelashes and eyebrows. Eur J Dermatol 2009; 19:586-7.

142. Coronel-Pérez IM, Rodríguez-Rey EM, Camacho-Martínez FM. Latanoprost in the treatment of eyelash alopecia in alopecia areata universalis. J Eur Acad Dermatol Venereol 2010;24:481-5.

143. Strazzulla LC, Wang EH, Avila L, Lo Sicco K, Brinster N, Christiano AM, et al. Alopecia areata: an appraisal of new treatment approaches and overview of current therapies. J Am Acad Dermatol 2018;78:15-24.

Conflicts of interest.-The authors certify that there is no conflict of interest with any financial organization regarding the material discussed in the manuscript. Authors' contributions.-Alfredo Rossi, Marta Muscianese and Maria C. Fortuna designed, wrote and edited the Italian guideline. Bianca M. Piraccini, Michela Starace, Luca Stingeni, Victor D. Mandel and Simone Garcovich reviewed the manuscrit. All the others authors collaborate in editing the manuscript. Acknowledgements.-The Authors acknowledge all the members of Italian Study Group on Cutaneous Annexial Disease of the Italian Society of Dermatology (SIDeMaST) for their contribution.

Article first published online: September 26, 2019. - Manuscript accepted: September 23, 2019. - Manuscript received: August 6, 2019. 